\title{
A Single Amino Acid Substitution in Hypervariable Region 5 of the Envelope Protein of Feline Immunodeficiency Virus Allows Escape from Virus Neutralization
}

\author{
KEES H. J. SIEBELINK, ${ }^{1}$ GUUS F. RIMMELZWAAN, ${ }^{1}$ MARNIX L. BOSCH, ${ }^{1}$ ROB H. MELOEN, ${ }^{2}$ \\ AND ALBERT D. M. E. OSTERHAUS ${ }^{1,3 *}$ \\ Laboratory of Immunobiology, National Institute of Public Health and Environmental Protection, Antonie \\ van Leeuwenhoeklaan 9, P.O. Box 1, 3720 BA Bilthoven, ${ }^{1}$ Central Veterinary Institute, 8200 AB Lelystad, ${ }^{2}$ \\ and Veterinary Faculty, Division of Virology, Institute of Infectious Diseases and Immunology, \\ State University of Utrecht, 3508 TD Utrecht, ${ }^{3}$ The Netherlands
}

Received 11 September 1992/Accepted 11 December 1992

\begin{abstract}
We infected a specific-pathogen-free cat (cat 14) with molecularly cloned feline immunodeficiency virus clone 19k1 (FIV19k1 [K. H. J. Siebelink, I. Chu, G. F. Rimmelzwaan, K. Weijer, A. D. M. E. Osterhaus, and M. L. Bosch, J. Virol. 66:1091-1097, 1992]). Serum of this cat obtained 22 weeks postinfection (serum 1422) neutralized FIV19k1 but not FIV19k32, which is $99.3 \%$ identical to FIV19k1 in the envelope gene. Serum 1422 also neutralized virus isolated from cat 14 at weeks 2 and 32 postinfection. We then cultured FIV19k1 in the continuous presence of serum 1422, which resulted in a delay in virus replication of 6 weeks. The resulting virus population appeared to be resistant to virus neutralization by serum 1422. Nucleotide sequencing of the env open reading frame of this presumed escape mutant revealed the presence of one silent and two substitution mutations, both of the latter in hypervariable region 5. Through the construction of chimeric viruses and site-directed mutagenesis, we demonstrated that one of these mutations, the substitution of lysine to glutamine at amino acid position 560 in hypervariable region 5, was sufficient to allow the escape of FIV19k1 from neutralization by serum 1422 .
\end{abstract}

Feline immunodeficiency virus (FIV) is a recently discovered T-lymphotropic lentivirus (28) which appeared to be the cause of an AIDS-like disease in naturally infected cats $(14$, $15,28,36,39,44)$. FIV resembles human immunodeficiency virus type 1 (HIV-1) in its biological and morphological properties. A decline in numbers of $\mathrm{CD}^{+}$lymphocytes observed in vivo and in vitro $(1,3,13,37)$, a gradual loss of immune function $(3,11,18,38,41,44)$, and the occurrence of opportunistic infections as in human AIDS make FIV infection in cats a useful small animal model for the study of HIV infections in humans.

Infection with lentiviruses, including FIV and HIV-1, generally results in persistence of the virus in the host, leading to a continuous interaction between the virus and the immune system $(4,6,21,22,24,25,44)$. Genetic variation allows the virus to escape from the continuous pressure exerted by antibodies $(20,32,43$; for a review, see reference 26) and cytotoxic T cells (29). Domains on the envelope glycoprotein that induce virus neutralizing (VN) antibodies have been determined $(7,10,12,17,40)$, and escape from VN antibodies has been described in various lentiviral systems. After infection with HIV-1, two types of VN serum antibodies are observed. Shortly after infection, type-specific neutralizing antibodies that are mainly targeted to the principal neutralizing determinant (PND) within variable region 3 arise $(10,27,34)$. Later in the course of infection, more broadly neutralizing antibodies in which other antigenic sites on the envelope protein are also involved are induced $(7,16,19,31$, 40; for a review, see reference 9$)$. The envelope gene of FIV is highly variable but exhibits, like the envelope gene of HIV-1, constant and more variable regions

* Corresponding author.
$(23,30,37)$. FIV neutralizing antibodies have been demonstrated in the sera of infected cats $(5,42)$, but the sites involved in their induction have not been identified. The generation of $\mathrm{VN}$ escape mutants and studies concerning the mechanisms leading to escape may provide more information about the structural and functional properties of these antigenic sites. Two mechanisms by which a lentivirus can escape from VN antibody pressure have been described. The first involves changes in the binding site itself, whereas the other involves changes elsewhere on the envelope glycoproteins $(20,43)$. The availability of molecular clones of HIV-1 has allowed the identification of the molecular basis underlying the escape of the virus from neutralizing antibody and has provided evidence that both mechanisms are operational $(20,32,43)$.

In an attempt to elucidate the mechanism by which FIV would escape from VN pressure, we have used the same approach. Thus, we have identified a single amino acid change in the envelope glycoprotein of FIV that leads to escape of the virus from neutralizing antibody.

\section{MATERIALS AND METHODS}

Virus. Viral progeny of replication-competent molecular clones 19k1 (FIV19k1) and 19k32 (FIV19k32) and the uncloned isolate FIV $\mathrm{A}^{\prime}$ dam 19 were obtained as described previously (37). A 10-week-old specific-pathogen-free (SPF) cat (cat 14) was infected with FIV19k1 by intraperitoneal inoculation of $10^{2} 50 \%$ tissue culture infectious doses. Virus was reisolated from this cat at 2 and 32 weeks postinfection (p.i.) and designated FIV19k1R2 and FIV19k1R32, respectively.

Sera. Serum of a naturally FIV infected cat, A'dam19, was designated serum A19 (37). Serum of cat 14 was taken prior to infection (preserum) and at 22 weeks p.i. (designated 
serum 1422). Serum of a noninfected SPF cat was used as a control serum (SPF serum). All sera were heat inactivated for $1 \mathrm{~h}$ at $56^{\circ} \mathrm{C}$ prior to use.

Gag- and Env-specific ELISAs. The presence of antibodies directed against the envelope protein of FIV was detected in a recombinant FIV envelope protein enzyme-linked immunosorbent assay (ELISA) as described elsewhere (33), and antibodies raised against Gag proteins were detected in a commercially available FIV p24/p17 antibody ELISA as recommended by the manufacturer (European Veterinary Laboratory, Amsterdam, The Netherlands).

RT assay. Reverse transcriptase (RT) activity was determined as previously described (37).

VN assay. Since low virus passage levels were used to avoid additional mutations by in vitro culturing, and the virus titer of the stocks propagated in feline peripheral blood mononuclear cells (PBMC) (37) was low (approximately $10^{2}$ ), we decided to standardize the viral input by RT activity. Virus stocks of FIV19k1, FIV19k32, the uncloned isolate FIV $A^{\prime}$ dam19, and the reisolates FIV19k1R2 and FIV19k1R32 were tested in an RT assay. For this assay, 450 $\mu l$ of diluted virus stocks containing RT activity of $5 \times 10^{4}$ $\mathrm{cpm} / \mathrm{ml}$ were incubated with $50 \mu \mathrm{l}$ of a serum sample for 60 min at $37^{\circ} \mathrm{C}$. Concanavalin A (ConA)- and interleukin-2 (IL-2)-stimulated PBMC $\left(10^{6}\right)$ were added. After $60 \mathrm{~min}$ at $37^{\circ} \mathrm{C}$, the cells were washed and incubated for 14 days in $\mathrm{CM}$ (RPMI 1640 [GIBCO], penicillin [100 IU/ml], streptomycin $[100 \mu \mathrm{g} / \mathrm{ml}]$, L-glutamine [2 $\mathrm{mM}], \beta$-mercaptoethanol $[2 \times$ $\left.10^{-5} \mathrm{M}\right]$, IL-2 [100 IU/ml]) supplemented with $2 \%$ of the respective serum sample. RT activity was determined as a measure for virus production. Virus neutralization was considered positive when the RT activity did not increase over two times the background level defined as the mean RT activity of uninfected cells. In previous experiments, it was observed that the RT activity of FIV-infected cultures was at least five times the background level (not shown).

Generation of escape mutants. ConA- and IL-2-stimulated PBMC of an SPF cat $\left(10^{6}\right)$ were infected with FIV19k1. After $24 \mathrm{~h}$, the cultures were divided between two identical flasks. To one of the cultures we added $2 \%$ serum 1422 , and to the other we added $2 \%$ SPF serum (control serum). The culture supernatants were harvested weekly, replaced with fresh CM supplemented with a $2 \%$ concentration of the respective serum, and tested for the presence of RT activity. When RT activity over five times background values was present, the supernatant was filtered through a $220-\mathrm{nm}$-pore-size filter and stored at $-135^{\circ} \mathrm{C}$. Viruses derived from these cultures were designated 19k1A and 19k1B when derived from cultures with serum 1422 or with SPF serum, respectively. Dilutions of the culture supernatants of $19 \mathrm{k} 1 \mathrm{~A}$ and $19 \mathrm{k} 1 \mathrm{~B}$ containing RT activity of $5 \times 10^{4} \mathrm{cpm} / \mathrm{ml}$ were incubated with $10 \%$ serum 1422 or SPF serum for $60 \mathrm{~min}$ at $37^{\circ} \mathrm{C}$. ConA and IL-2stimulated PBMC of an SPF cat $\left(10^{6}\right)$ were added to each culture. After $60 \mathrm{~min}$ of incubation at $37^{\circ} \mathrm{C}$, the cells were washed and cultured in $\mathrm{CM}$ supplemented with a $2 \%$ concentration of the respective serum. The culture supernatant was tested for the presence of RT activity twice a week. When RT activity could be demonstrated, the culture supernatant was filtered through a 220-nm-pore-size filter and stored at $-135^{\circ} \mathrm{C}$. The viruses were designated $19 \mathrm{k} 1 \mathrm{~A}, \mathrm{~A}$ and $19 \mathrm{k} 1 \mathrm{~A}, \mathrm{~B}$ for $19 \mathrm{k} 1 \mathrm{~A}$ propagated in the presence of serum 1422 and SPF serum, respectively, and 19k1B,A and 19k1B,B for 19k1B propagated in the presence of serum 1422 and SPF serum, respectively. 19k1A,A was further designated 19k1esc.

Sequence analysis. The sequence of the envelope gene of $19 \mathrm{k} 1$ has been described previously (37). The envelope gene of the escape mutant $19 \mathrm{klesc}$ was amplified by polymerase chain reaction (PCR). PBMC $\left(10^{5}\right)$ from the $19 \mathrm{klesc}$ culture were pelleted and lysed with $100 \mu \mathrm{l}$ of $\mathrm{K}$ buffer $(50 \mathrm{mM} \mathrm{KCl}$, $10 \mathrm{mM}$ Tris [pH 8.4], $1.5 \mathrm{mM} \mathrm{MgCl} 2,0.5 \%$ Tween $20,100 \mu \mathrm{g}$ of proteinase $\mathrm{K}$ per $\mathrm{ml}$ ) for $45 \mathrm{~min}$ at $56^{\circ} \mathrm{C}$. The reaction was stopped by incubating the mixture for $5 \mathrm{~min}$ at $95^{\circ} \mathrm{C}$. Two oligonucleotide primers were designed (primer 1, 5'-GGC GAATTCATGGCAGAAGGATTTGTAGCC-3'; primer 2, 5'TATGCATGCTCATTCCTCCTCTTTTTCAGACATGCC$\left.3^{\prime}\right)$ which contained EcoRI and SphI restriction enzyme cleavage sites (underlined), respectively, to facilitate subsequent cloning into pUC19. PCRs were carried out in a separate laboratory (to avoid contamination) in a volume of $100 \mu \mathrm{l}$ containing $10 \mu \mathrm{l}$ of the cell lysate, $50 \mathrm{mM} \mathrm{KCl}, 10 \mathrm{mM}$ Tris (pH 8.4), $1.5 \mathrm{mM} \mathrm{MgCl}_{2}, 0.02 \%$ gelatin, $250 \mu \mathrm{M}$ deoxynucleoside triphosphates, $1 \mu \mathrm{M}$ each primer, and 2.5 $\mathrm{U}$ of Taq polymerase. Samples were overlaid with $100 \mu \mathrm{l}$ of mineral oil to avoid evaporation and then subjected to 35 amplification cycles consisting of a denaturing step $\left(94^{\circ} \mathrm{C}, 1\right.$ $\mathrm{min})$, a primer-annealing step $\left(60^{\circ} \mathrm{C}, 1 \mathrm{~min}\right)$, and a primer extension step $\left(72^{\circ} \mathrm{C}, 2 \mathrm{~min}\right)$. Negative controls (noninfected PBMC from an SPF cat) were amplified in parallel. Amplification products were analyzed by agarose gel electrophoresis $(0.8 \%)$ for the presence of the appropriately sized DNA fragments. Excess primers in the PCR were eliminated by using a Centricon-30 microconcentrator (Amicon). DNA was digested with EcoRI and SphI and cloned into pUC19. The subclone was used for the dideoxynucleotide chain termination reaction (35) of the envelope gene. The nucleotide and protein alignments were done with Lasergene software (DNAstar Inc., London, United Kingdom). The observed nucleotide variation of 19klesc was confirmed by using an independent PCR amplification to exclude Taq errors.

Generation of chimeric clones. The construction of chimeric clones is schematically represented in Fig. 1. Restriction mapping identified a common and a unique internal SphI site in both FIV genomes. To generate recombinant viruses, the lambda clones $19 \mathrm{k} 1$ and $19 \mathrm{k} 32$ were digested with SalI and SphI. The SalI and SphI fragments generated after digestion were cloned into plasmid vector pUC19 from which the KpnI site had been deleted. The plasmids containing the $5^{\prime}$ long terminal repeat, gag, and $5^{\prime}$ part of pol were designated $5^{\prime}$ subclones. Plasmids containing the $3^{\prime}$ part of pol, env, and $3^{\prime}$ long terminal repeat were designated $3^{\prime}$ subclones and were used to exchange internal 1,662-bp KpnI fragments between clones $19 \mathrm{k} 1$ and $19 \mathrm{k} 32$.

The 1,662-bp KpnI fragment of clone $19 \mathrm{k} 1$ was also cloned into pUC19 and was designated the $3^{\prime} \mathrm{KK}$ subclone of $19 \mathrm{k} 1$. A 144-bp NsiI-MstII fragment of the 19klesc envelope (see above) was exchanged, as was a 144-bp NsiI-MstII fragment of clone $19 \mathrm{k} 1$ in which one nucleotide was substituted by site-directed mutagenesis at either position 1667 or position 1678. Site-directed mutagenesis was performed by PCR on the $3^{\prime}$ subclone of $19 \mathrm{k} 1$. To that end, three oligonucleotides were designed. Primer 1 (5'-CCTTATTATGCATTTCAA TATGACAAAAGCTG-3') contained an NsiI site (underlined); primer mut1 (5'-GCCTTTTTCCTCAGGACATTCC ATTTTTATTGTGTGAGTATTG-3') contained an MstII site (underlined) and a T-to-G substitution at position 1667 (italic); primer mut2 (5'-GCCTTTTTCCTCAGGACATTC CATTTGTATTG-3') contained an MstII site (underlined) and a T-to-G substitution at position 1678 (italic). Two PCRs were carried out, using in both reactions primer 1 to prime from the $5^{\prime}$ end. In one reaction primer mut1 was used while in the other reaction primer mut 2 was used to prime from the $3^{\prime}$ end. The conditions for PCR are described above. PCR 


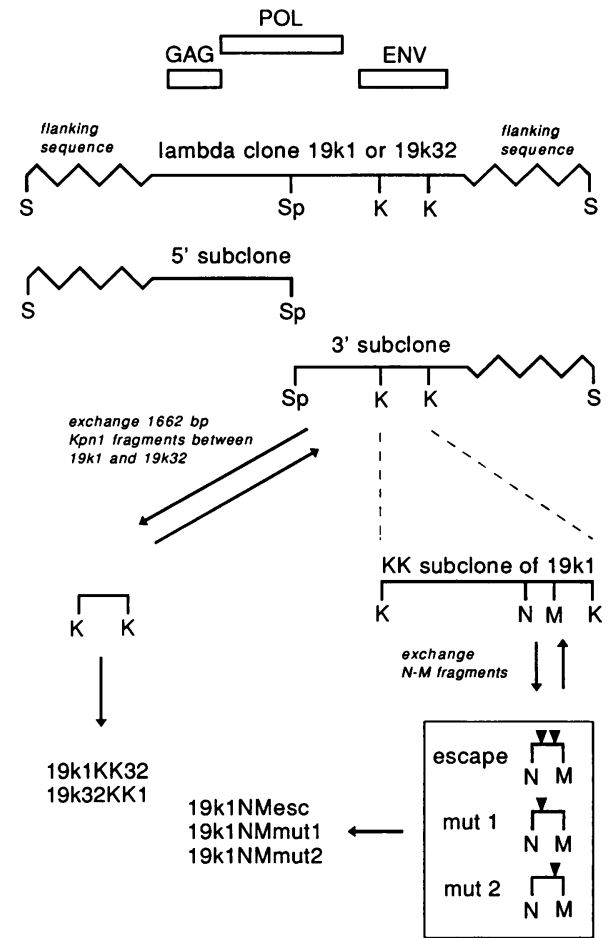

FIG. 1. Schematic representation of the construction of chimeric FIV clones (see text for details). The uppermost bars represent the major open reading frames gag, pol, and env. Restriction enzyme cleaving sites are indicated as follows: K, KpnI; M, MstII; N, NsiI; S, SalI; Sp, SphI. Individual point mutations are indicated $(\nabla)$.

fragments were digested with $N s i$ I and MstII and cloned into the $3^{\prime} \mathrm{KK}$ subclone of $19 \mathrm{k} 1$. The mutagenesis was confirmed by sequence analysis.

The 1,662-bp KpnI fragments from the $3^{\prime} \mathrm{KK}$ subclones in which 144-bp NsiI and MstII fragments were exchanged were cloned into the $3^{\prime}$ subclone of $19 \mathrm{k} 1 ; 2.5-\mu \mathrm{g}$ amounts of each of the $3^{\prime}$ subclones and the $5^{\prime}$ subclones were mixed, digested with SphI, and ligated. After digestion with SalI, the constructs were transfected into Crandell feline kidney (CrFK) cells as previously described (37). Virus production was rescued by cocultivation of transfected cells with ConAand IL-2-stimulated PBMC for 3 days. Cultures were monitored for syncytium formation of PBMC and RT activity in the culture supernatant. When RT activity could be measured, culture supernatant was filtered through an $220-\mathrm{nm}$ pore-size filter and stored in aliquots at $-135^{\circ} \mathrm{C}$.

Synthesis and reaction of peptides with sera. Twelve-mer peptides with an overlapping sequence of 11 amino acids were synthesized and analyzed for reactivity with sera as previously described (8). The amino acid sequences of the peptides were based on the amino acid sequences of the envelope proteins of clones $19 \mathrm{k} 1$ and $19 \mathrm{k} 1$ esc between amino acid positions 549 and 583. Three 12-mer control peptides with an overlapping sequence of eight amino acids were synthesized according to the epitope between positions 596 and 616 as described by Avrameas et al. (2).

\section{RESULTS}

Infection of cats. Upon experimental infection with viral progeny of clone $19 \mathrm{k} 1$, cat 14 seroconverted within 4 weeks. The Gag- and Env-specific serum antibodies measured by
TABLE 1. Anti-FIV serum antibody response of cat 14 determined by Gag- and Env-specific ELISA and virus isolation after infection with FIV19k1 of cat 14

\begin{tabular}{lrcc}
\hline & \multicolumn{2}{c}{ Antibody response } & \\
\cline { 2 - 4 } p.i. & $\begin{array}{c}\text { Gag } \\
\left(\mathrm{OD}_{450}{ }^{a}\right.\end{array}$ & $\begin{array}{c}\text { Env (reciprocal } \\
\text { titer) }\end{array}$ & $\begin{array}{c}\text { Virus } \\
\text { isolation }\end{array}$ \\
\hline 0 & $\left.\left.<10^{-3}\right]\right)$ & $<40$ & $\mathrm{ND}^{b}$ \\
2 & $<50$ & 40 & + \\
4 & 750 & 640 & $\mathrm{ND}$ \\
6 & 722 & $>5,120$ & $\mathrm{ND}$ \\
8 & 1,031 & $>5,120$ & $\mathrm{ND}$ \\
11 & 1,186 & $>5,120$ & $\mathrm{ND}$ \\
22 & 1,079 & $>5,120$ & $\mathrm{ND}$ \\
32 & 1,036 & $>5,120$ & + \\
\hline
\end{tabular}

${ }^{a} \mathrm{OD}_{450}$, optical density at $450 \mathrm{~nm}$

${ }^{b} \mathrm{ND}$, not determined.

ELISA reached plateau levels within 8 weeks after infection (Table 1). Virus was reisolated 2 and 32 weeks p.i. (Table 1). The serum collected 22 weeks p.i. (serum 1422) and the two virus isolates (FIV19k1R2 and FIV19k1R32, respectively) from this cat were used in the experiments described below.

VN activity. Serum from cat 14 (serum 1422) was tested for VN activity against FIV19k1, FIV19k32, and the uncloned isolates FIV A'dam19, FIV19k1R2, and FIV19k1R32. SPF serum was used as a control. The results are listed in Table 2. Virus replication as determined by RT activity was demonstrated in all cultures in the presence of SPF serum. Replication of virus was detected in the presence of serum 1422 in the cultures of FIV19k32 and the uncloned isolate FIV A'dam19. However, no virus replication was detected in the culture infected with FIV19k1 and the reisolates FIV19k1R2 and FIV19k1R32 cultured in the presence of serum 1422, indicating complete neutralization. Serum 1422 which was absorbed with protein A-Sepharose beads to remove antibodies (particularly immunoglobulin $G$ ) failed to neutralize molecular clone $19 \mathrm{k} 1$, which indicates that serum immunoglobulin is responsible for the observed neutralizing activity (not shown).

Generation of escape mutants. FIV19k1-infected PBMC from an SPF cat were cultured in the presence of serum 1422 (culture A) or SPF serum (culture B). Within 17 days, RT activity could be measured in the supernatant of culture $B$. After 44 days of culture, RT activity was detected in culture A (Fig. 2A). RT activity increased during time of culture. No RT activity could be demonstrated in the noninfected cultures which were cultured in the presence of serum 1422 or SPF serum for 52 days of culture (data not shown).

The supernatants of cultures A and B were collected, filtered 52 days p.i., and designated $19 \mathrm{k} 1 \mathrm{~A}$ and $19 \mathrm{k} 1 \mathrm{~B}$,

TABLE 2. Virus neutralization of an FIV isolate, molecular clones, and FIV reisolates with serum 1422 and SPF serum

\begin{tabular}{lcc}
\hline \multirow{2}{*}{ Virus } & \multicolumn{2}{c}{ RT activity $(\mathrm{cpm} / \mathrm{ml}$ ) after neutralization } \\
with:
\end{tabular}



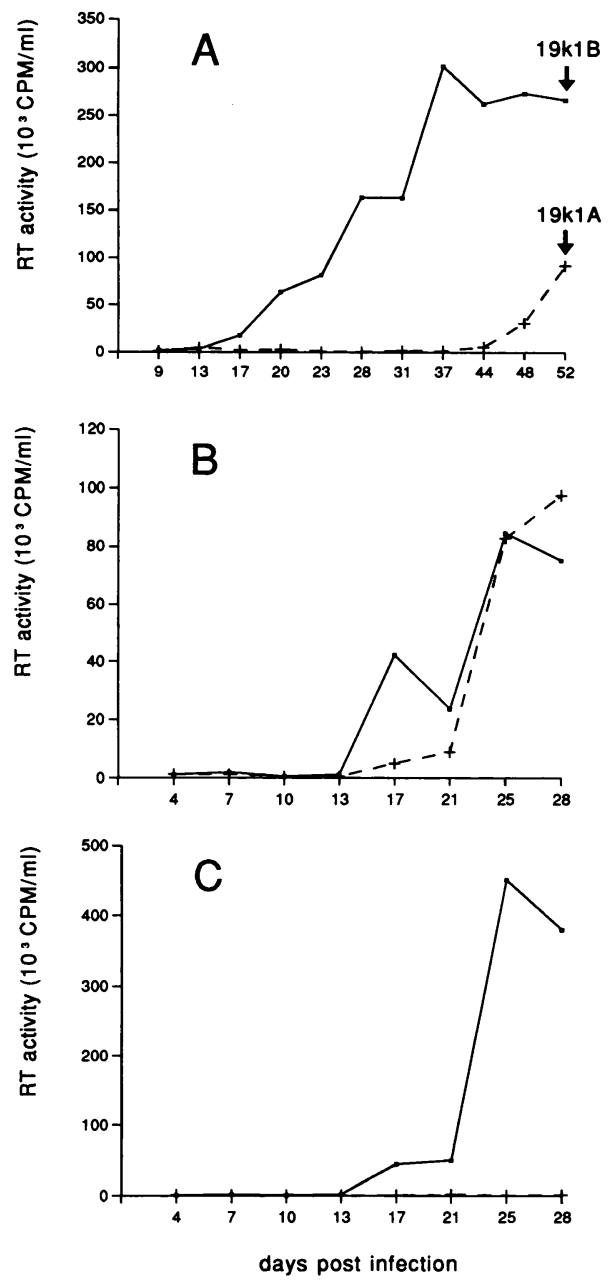

FIG. 2. Kinetics of virus replication expressed as RT activity of FIV19k1 (A), FIV19k1A (B), and FIV19k1B (C) in the presence of serum 1422 (dashed line) or SPF serum (solid line).

respectively. These culture supernatants were incubated with serum 1422 or SPF serum. ConA- and IL-2-stimulated PBMC from an SPF cat were added to the virus-serum mixture and cultured further in the presence of the respective serum, serum 1422 or SPF serum. The cultures were designated $19 \mathrm{k} 1 \mathrm{~A}, \mathrm{~A}$ and $19 \mathrm{k} 1 \mathrm{~A}, \mathrm{~B}$ for the cultures of $19 \mathrm{k} 1 \mathrm{~A}$ cultured in the presence of serum 1422 or SPF serum, respectively (Fig. 2B) and 19k1B,A and 19k1B,B for the cultures of $19 \mathrm{k} 1 \mathrm{~B}$ cultured in the presence of serum 1422 or SPF serum, respectively (Fig. 2C). RT activity was demonstrated after 17 days of infection in both cultures of $19 \mathrm{k} 1 \mathrm{~A}$. The kinetics of virus replication of $19 \mathrm{k} 1 \mathrm{~A}, \mathrm{~A}$ were similar to those of the control 19k1A,B (Fig. 2B) and 19k1B,B (Fig. 2C). As expected, no virus replication was observed in the culture 19k1B,A (Fig. 2C). These results show that 19k1A,A is resistant to virus neutralization by serum 1422 .

Sequence analysis. Cells of culture 19k1A,A further designated 19k1esc were lysed, and the envelope gene of the FIV genome, integrated in the cellular DNA, was amplified by PCR. The PCR product was digested with EcoRI and SphI and cloned into pUC19. The envelope gene of $19 \mathrm{klesc}$ was sequenced and compared with the envelope sequences of the parental clone $19 \mathrm{k} 1$ and clone $19 \mathrm{k} 32$ (Fig. 3). At position 468 in hypervariable region 2 (HV-2), we observed a silent

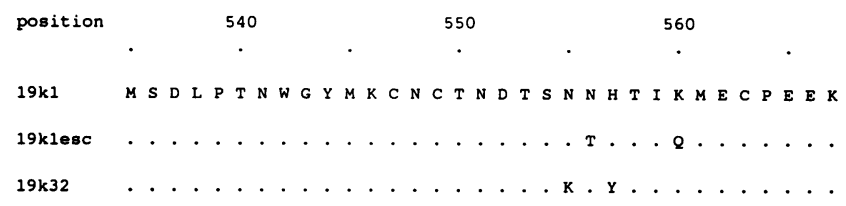

FIG. 3. Comparison of the amino acid sequences of HV-5 of the envelope genes of molecular clones $19 \mathrm{kl}, 19 \mathrm{k} 32$, and $19 \mathrm{klesc}$.

transition of $\mathrm{T}$ to $\mathrm{C}$ (not shown). Two A-to-C transversions were observed in HV-5. One at position 1667 causes an amino acid substitution of asparagine to threonine (amino acid position 556), whereas the other at position 1678 causes an amino acid substitution of lysine to glutamine (amino acid position 560). Comparison of the nucleotide sequences of the envelope genes of clone $19 \mathrm{k} 1$ and clone $19 \mathrm{k} 32$, which exhibited the same phenotype as did 19klesc in a VN assay using serum 1422, showed the presence of a T-to-G transversion at position 1665 and a transition of $C$ to $T$ at position 1669 , resulting in substitutions of asparagine with lysine (amino acid position 555) and histidine with tyrosine (amino acid position 557 ), respectively (Fig. 3 ).

Virus neutralization of chimeric clones. Viral progeny of the parental clone $19 \mathrm{k} 1$ and of those in which the envelope gene had been exchanged partially or an amino acid had been substituted by site-directed mutagenesis and the escape mutant 19klesc were incubated with serum 1422 or SPF serum prior to infection of ConA- and IL-2-stimulated thymocytes. The results of this experiment are similar to those of a number of previous experiments in which the chimeric clones were tested separately for neutralization by serum 1422. RT activity was measured 9 and 12 days p.i. RT activity could be measured in all control cultures 9 days p.i. and continued to increase through 12 days p.i. (Fig. 4). As expected, FIV19k1 was neutralized by serum 1422 and not by the SPF serum (Fig. 4A). As before, FIV19k32 was not neutralized by serum 1422 (Fig. 4B). To investigate whether the difference in virus neutralization between the two molecular clones was caused by the differences in the surface protein, we exchanged the 1,662-bp KpnI fragment. The chimeric clones were designated 19k1KK32 (19k1 containing the KpnI fragment of 19k32) and 19k32KK1 (19k32 containing the KpnI fragment 19k1). Chimeric clone 19k1KK32 was not neutralized, whereas chimeric clone $19 \mathrm{k} 32 \mathrm{KK} 1$ was neutralized with serum 1422 (not shown), indicating that an epitope within the 1,662-kb KpnI fragment of the envelope gene is involved in neutralization.

The escape mutant of FIV19k1, grown in the presence of serum 1422, was not neutralized by this serum (Fig. 4C). Comparison of the amino acid sequence of the envelope protein of $19 \mathrm{k} 1$ and the sequence of the escape mutant showed two amino acid substitutions within HV-5. To study whether these substitutions underlie the escape of FIV19k1 from serum 1422, we exchanged the 144-bp NsiI-MstII fragment, containing the whole HV-5, of clone $19 \mathrm{k} 1$ with that of the escape mutant. This chimera, designated 19k1NMesc, was not neutralized by serum 1422 (Fig. 4D), indicating that one or both amino acid substitutions are involved in the escape mechanism. By site-directed mutagenesis, the two amino acids were substituted separately. These point-mutated clones were designated 19k1mut1 (position 556, Asn to Thr) and 19k1mut2 (position 560, Lys to Gln). FIV19k1mut1 was neutralized by serum 1422 (Fig. 4E), whereas FIV19k1mut 2 could not be neutralized by serum 

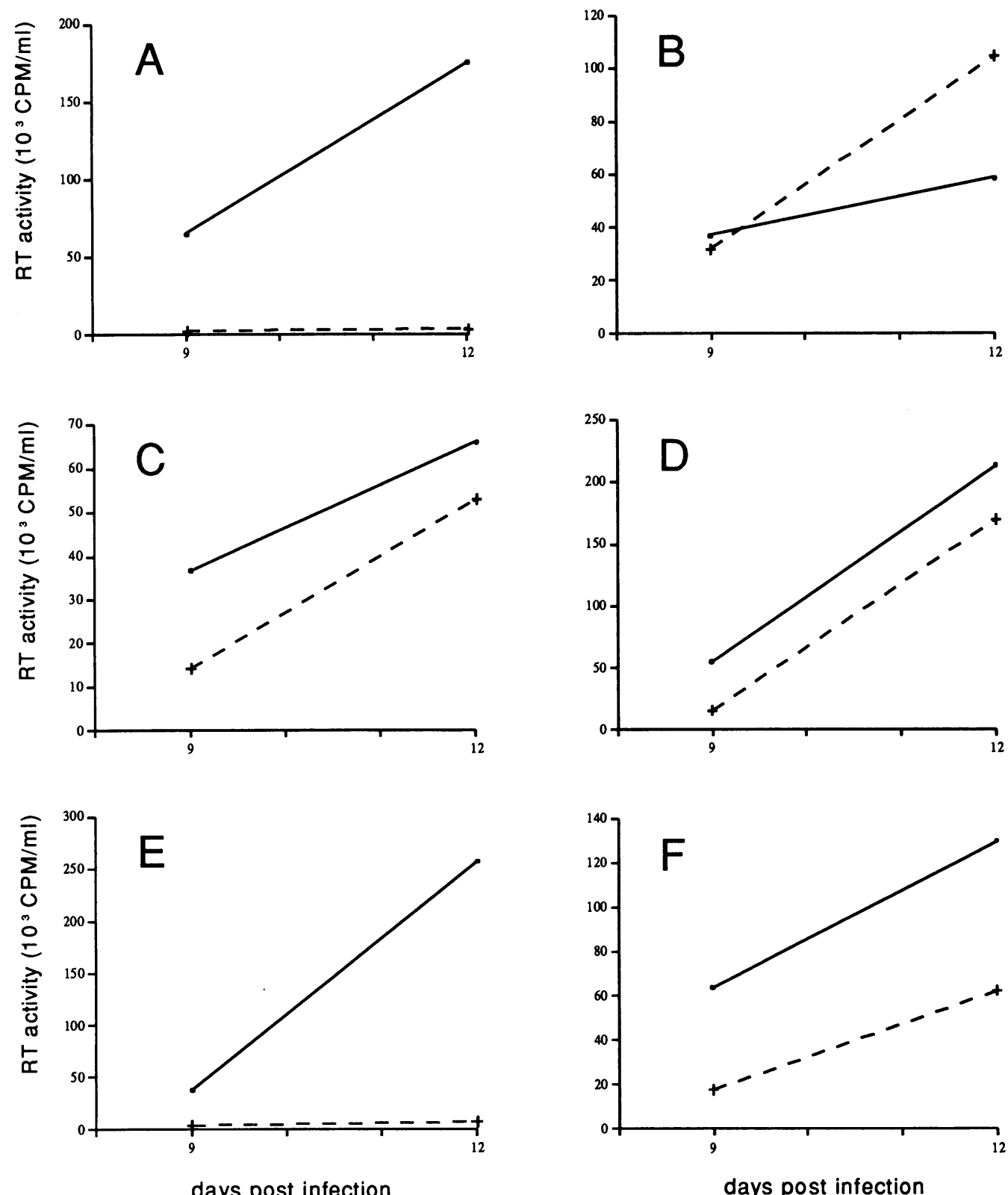

FIG. 4. Neutralization of viral progeny of parental and chimeric FIV clones and 19k1esc with serum 1422 (dashed line) or SPF serum (solid line) as determined by measuring RT activity. (A) FIV19k1; (B) FIV19k32; (C) FIV19k1esc; (D) FIV19k1NMesc; (E) FIV19k1mut1; (F) FIV19k1mut2.

1422 (Fig. 4F), indicating that the point mutation at amino acid position 560 resulting in an amino acid substitution from lysine to glutamine is responsible for escape of FIV19k1 from serum 1422 .

To investigate whether the differences in HV-5 between clones $19 \mathrm{k} 1$ and $19 \mathrm{k} 32$ also underlie differences in neutralization with serum 1422 , we reciprocally exchanged the 144-bp NsiI-MstII fragment between the two clones. This exchange, however, did not result in a change in virus neutralization (not shown), indicating that yet another epitope is involved.

Pepscan analysis. Twelve-mer peptides representing the amino acid sequence of the clones $19 \mathrm{k} 1$ and the escape mutant 19klesc between amino acid positions 549 and 583 were analyzed for reactivity with serum 1422 , serum from a naturally FIV infected cat, A'dam19, (serum A19), and SPF serum. As a control for the peptide scanning (pepscan) procedure, three 12-mer peptides spanning, with an overlap of eight amino acids, a previously described linear epitope on the envelope protein of FIV (from amino acid positions 596 to 616) were scanned with serum 1422, serum A19, and SPF serum. No reactivity in these sera was detected with the HV-5 peptides, whereas serum 1422 and serum A19 did react in the control pepscan (not shown), suggesting that no linear B-cell epitope in the C-terminal half of $\mathrm{HV}-5$ is recognized by serum 1422 and serum A19. 


\section{DISCUSSION}

In this report, we have demonstrated that a single amino acid substitution in the HV-5 region of the surface glycoprotein of FIV (amino acid position 560) allows a molecular clone of FIV to escape neutralization by the serum of a cat infected with this clone. Pepscan analysis of the region around amino acid 560 with and without the substitution showed no reactivity of the peptides with sera from cats infected with the molecular clone or with an uncloned isolate of FIV from the same origin. This finding suggests that the B-cell epitope involved in the escape either is dependent on its three-dimensional configuration or is located outside the region where the substitution took place. In the latter case, the amino acid substitution should have altered an epitope at a distant site. Similar studies with escape mutants of molecularly cloned HIV-1 have shown that an amino acid substitution in the PND may directly result in the escape from neutralization by a PND-specific monoclonal antibody (20). Others have shown that an amino acid substitution in the transmembrane glycoprotein of HIV-1 induced resistance to neutralization by sera from seropositive individuals (32). The basis for this resistance was shown to be most likely a conformational change altering a neutralization-inducing determinant at a distant site (43). To elucidate the mechanism involved in the escape from neutralization observed in the FIV system, further studies identifying antigenic sites that induce virus neutralization will be necessary.

Our data, which showed that an FIV escape mutant could readily be generated in the presence of VN serum antibody, suggest the predominance of type-specific VN antibodies in serum 1422 . The finding that one amino acid substitution allowed FIV19k1 to escape from neutralization by the cat serum collected 22 weeks p.i. indicates that this substitution affects a dominant VN antibody-inducing determinant against which the majority of $\mathrm{VN}$ antibodies in this serum are directed during the first months of infection. Another explanation would be that this substitution influences more than one VN antibody-inducing epitope. The observation by Tozzini et al. (42) and Fevereiro et al. (5) that within 4 weeks after FIV infection, serum antibodies with broad VN activity can be detected suggests that as in HIV-1 infection of humans, broadly reactive $\mathrm{VN}$ antibodies are formed. It should, however, be stressed that the VN assays that they used were carried out with FIV strains adapted to replication in a continuous fibroblastoid feline kidney cell (CrFK) line, whereas our VN assays were carried out in primary cat lymphocytes or thymocytes. Lymphoid cells, which are the natural target cells for FIV replication in vivo, can readily be infected with all strains of FIV, whereas only few FIV strains could be adapted to replication in CrFK cells. The genetic basis for this adaptation is currently unknown, but since upon transfection with proviral DNA, CrFK cells may produce FIV that cannot reinfect CrFK cells, virus entry is probably the limiting step. Therefore, it may be speculated that the broad neutralization observed in the assays based on CrFK cell-adapted FIV strains specifically interferes with the process underlying this limiting step.

Our future studies to elucidate the structural basis of FIV neutralization will also be based on the observations made with FIV19k32. This virus, like FIV19k1esc, was not neutralized by serum 1422. Exchange of the NsiI-Mst II fragment of $19 \mathrm{k} 1$ for the homologous fragment of $19 \mathrm{k} 32$, which contains the HV-5 region, could not confer resistance to $19 \mathrm{k} 1$. Since exchanging the 1,662-bp KpnI fragment between 19k1 and $19 \mathrm{k} 32$ resulted in transfer of the neutralization-resistant phenotype and the envelope proteins of $19 \mathrm{k} 1$ and $19 \mathrm{k} 32$ differ in only six amino acids, two of which are located within the HV-5 region (Fig. 3), genetic exchange experiments will reveal the exact location of additional regions involved in escape from virus neutralization.

As in other lentivirus infections, VN antibodies and cytotoxic $\mathrm{T}$ cells may be expected to play a crucial role in the pathogenesis of and the protective immunity against FIV infections. Therefore, detailed analysis of antigenic sites of FIV involved in the induction of $\mathrm{VN}$ antibodies and the mechanism leading to VN-resistant FIV variants will lead to a better understanding of lentivirus pathogenesis and help in the design of effective lentivirus vaccines.

\section{ACKNOWLEDGMENTS}

We thank C. Kruyssen for preparing the manuscript, W. Puyk for performing the pepscan analysis, and R. van Herwijnen for performing the Gag-specific ELISA. We also thank G. van Amerongen and N. Schmidt for biotechnical assistance.

This work was supported by the Advisory Council on Health Research (RGO no. 88-90/89028) and the Concerted Action on Feline AIDS of the European Community.

\section{REFERENCES}

1. Ackley, C. D., J. K. Yamamoto, N. Levy, N. C. Pedersen, and M. D. Cooper. 1990. Immunologic abnormalities in pathogenfree cats experimentally infected with feline immunodeficiency virus. J. Virol. 64:5652-5655.

2. Avrameas, A., J. Guillet, L. Chouchane, A. Moraillon, P. Sonigo, and A. D. Strosberg. 1992. Localization of three epitopes of the env protein of feline immunodeficiency virus. Mol. Immunol. 29:565-572.

3. Barlough, J. E., C. D. Ackley, J. W. George, N. Levy, R. Acevedo, P. F. Moore, B. A. Rideout, M. D. Cooper, and N. C. Pedersen. 1991. Acquired immune dysfunction in cats with experimentally induced feline immunodeficiency virus infection: comparison of short-term and long-term infections. J. Acquired Immune Defic. Syndr. 4:219-227.

4. Fauci, S. A. 1988. The human immunodeficiency virus: infectivity and mechanism of pathogenesis. Science 239:617-622.

5. Fevereiro, M., C. Roneker, A. Laufs, L. Tavares, and F. de Noronha. 1991. Characterization of two monoclonal antibodies against feline immunodeficiency virus gag gene products and their application in an assay to evaluate neutralizing activity. $J$. Gen. Virol. 72:617-622.

6. Franchini, G., P. Markham, E. Gard, K. Fargnoli, S. Keubaruwa, L. Jagodzini, M. Robert-Guroff, P. Lusso, G. Ford, F. Wong-Staal, and R. C. Gallo. 1990. Persistent infection of rhesus macaques with a molecular clone of human immunodeficiency virus type 2: evidence of minimal genetic drift and low pathogenic effects. J. Virol. 64:4462-4467.

7. Fung, M. S. C., C. R. Y. Sun, W. L. Gordon, R. Liou, T. W. Chang, W. N. C. Sun, E. S. Daar, and D. D. Ho. 1992. Identification and characterization of a neutralization site within the second variable region of human immunodeficiency virus type 1 gp120. J. Virol. 66:848-856.

8. Geijsen, H. M., R. H. Meloen, and S. J. Barteling. 1984. Use of peptide synthesis to probe viral antigens for epitopes to a resolution of a single amino acid. Proc. Natl. Acad. Sci. USA 81:3998-4002.

9. Goudsmit, J. 1992. Humoral immune responses in human HIV-1 infection clearance of initial burst of virus replication and protection against disease progression. Int. Rev. Immunol. 8:65-81.

10. Goudsmit, J., C. Debouck, R. H. Meloen, L. Smit, M. Bakker, D. M. Asher, A. V. Wolf, C. J. Gibbs, and C. D. Gajdusek. 1988. Human immunodeficiency virus type 1 neutralization epitope with conserved architecture elicit early type-specific antibodies in experimentally infected chimpanzees. Proc. Natl. Acad. Sci. USA 85:4478-4482.

11. Hara, Y., T. Ishida, H. Ejima, M. Tagawa, S. Motoyoshi, I. 
Tomoda, M. Shimizu, and K. Shichinohe. 1990. Decrease in mitogen-induced lymphocyte proliferative responses in cats infected with feline immunodeficiency virus. Jpn. J. Vet. Sci. 52:573-579.

12. Ho, D. D., J. A. McKeating, X. L. Li, T. Moudgil, E. S. Daar, N. Sun, and J. E. Robinson. 1991. Conformational epitope on gp120 important in CD4 binding and human immunodeficiency virus type 1 neutralization identified by a human monoclonal antibody. J. Virol. 65:489-493.

13. Hoffmann-Fezer, G., J. Thum, C. Ackley, M. Herbold, J. Mysliwietz, S. Thefeld, K. Hartmann, and W. Kraft. 1992. Decline in $\mathrm{CD}^{+}$cell numbers in cats with naturally acquired feline immunodeficiency virus infection. J. Virol. 66:1484-1488.

14. Hopper, C. D., A. H. Sparkes, T. J. Gruffydd-Jones, S. M. Crispin, P. Muir, D. A. Harbour, and C. R. Stokes. 1989. Clinical and laboratory findings in cats infected with feline immunodeficiency virus. Vet. Rec. 125:341-346.

15. Hosie, M. J., C. Robertson, and O. Jarrett. 1989. Prevalence of feline leukaemia virus and antibodies to feline immunodeficiency virus in cats in the United Kingdom. Vet. Rec. 128:293297.

16. Kang, C., P. Nara, S. Chamat, V. Caralli, T. Ryskamp, N. Haigwood, R. Newman, and H. Köhler. 1991. Evidence for non-V3-specific neutralizing antibodies that interfere with gp120/CD4 binding in human immunodeficiency virus 1-infected humans. Proc. Natl. Acad. Sci. USA 88:6171-6175.

17. Kodama, T., D. P. W. Burns, D. P. Silva, F. Dimarzo Veroneze, and R. C. Desrosiers. 1991. Strain-specific neutralizing determinant in the transmembrane protein of simian immunodeficiency virus. J. Virol. 65:2010-2018.

18. Lin, D. S., D. D. Bowman, R. H. Jacobson, M. C. Barr, M. Fevereiro, J. R. Williams, F. M. O. Noronha, F. W. Scott, and R. J. Avery. 1990. Suppression of lymphocyte blastogenesis to mitogens in cats experimentally infected with feline immunodeficiency virus. Vet. Immunol. Immunopathol. 26:183-189.

19. Matsushida, S., M. Robert-Guroff, J. Rusche, A. Koito, T. Hattori, H. Hoshino, K. Javaherian, K. Takatsuki, and S. Putney. 1988. Characterization of a human immunodeficiency virus neutralizing monoclonal antibody and mapping of the neutralizing epitope. J. Virol. 62:2107-2114.

20. McKeating, J. A., J. Gow, J. Goudsmit, L. H. Pearl, C. Mulder, and R. A. Weiss. 1989. Characterization of HIV-1 neutralization escape mutants. AIDS 3:777-784.

21. Melbye, M., R. J. Biggar, P. Ebbesen, C. Neuland, J. J. Goedert, V. Faber, I. Lorenzen, P. Skinhøj, R. C. Gallo, and W. A. Blattner. 1986. Long-term seropositivity for human T-lymphotropic virus type III in homosexual men without the acquired immunodeficiency syndrome: development of immunologic and clinical abnormalities. Ann. Int. Med. 104:496-500.

22. Montelaro, R. C., B. Parekh, A. Orrego, and J. Issel. 1984. Antigenic variation during persistent infection by equine infectious anaemia virus, a retrovirus. J. Biol. Chem. 256:1053910544.

23. Morikawa, S., H. Lutz, A. Aubert, and D. H. L. Bishop. 1991. Identification of conserved and variable regions in the envelope glycoprotein sequences of two feline immunodeficiency viruses isolated in Zurich, Switzerland. Virus Res. 21:53-63.

24. Narayan, O., D. E. Griffin, and J. Chase. 1977. Antigenic shift of visna virus in persistently infected sheep. Science 197:376-378.

25. Nicol, I., G. Flamminio-Zola, P. Dubouch, J. Bernard, R. Snart, R. Joufire, B. Reveil, M. Fouchard, I. Desportes, P. Nara, R. C. Gallo, and D. Zagury. 1989. Persistent HIV-2 infection of rhesus macaque, baboon, and mangabeys. Intervirology 30:258-267.

26. Oldstone, M. B. A. 1991. Molecular anatomy of viral persistence. J. Virol. 65:6381-6386.

27. Palker, T. J., M. E. Clark, A. J. Langlois, T. J. Matthews, K. J. Weinhold, R. R. Randall, D. P. Bolognesi, and B. F. Haynes. 1988. Type-specific neutralization of the human immunodeficiency virus with antibodies to env-encoded synthetic peptides. Proc. Natl. Acad. Sci. USA 85:1932-1936.

28. Pedersen, N. C., E. W. Ho, M. L. Brown, and J. K. Yamamoto. 1987. Isolation of a T-lymphotropic virus from domestic cats with an immunodeficiency-like syndrome. Science 235:790-793.
29. Phillips, R. E., S. Rowland-Jones, D. F. Nixon, F. M. Gotch, J. P. Edwards, A. O. Ogunlesi, J. G. Elvin, J. A. Rothbard, C. R. M. Bangham, C. R. Rizza, and A. J. McMichael. 1991. Human immunodeficiency virus genetic variation that can escape cytotoxic $T$ cell recognition. Nature (London) 354:453459.

30. Phillips, T. R., R. L. Talbott, C. Lamont, D. Muir, K. Lovelace, and J. H. Elder. 1990. Comparison of two host cell range variants of feline immunodeficiency virus. J. Virol. 64:4605-4613.

31. Profy, A. T., P. A. Salinas, L. I. Eckler, N. M. Dunlop, P. L. Nara, and S. C. Putney. 1990. Epitopes recognized by the neutralizing antibodies of an HIV-1 infected individual. J. Immunol. 144:4641-4647.

32. Reitz, M. S., C. Wilson, C. Naugle, R. C. Gallo, and M. Robert-Guroff. 1988. Generation of a neutralization-resistant variant of HIV-1 is due to selection for a point mutation in the envelope gene. Cell 54:57-63.

33. Rimmelzwaan, G. F., K. H. J. Siebelink, H. Broos, G. A. Drost, K. Weijer, R. V. Herwijnen, and A. D. M. E. Osterhaus. Gagand env-specific serum antibodies in cats after natural and experimental infection with feline immunodeficiency virus. Submitted for publication.

34. Rusche, J. R., K. Javaherian, C. McDanal, J. Petro, D. L. Lynn, A. Grimaila, A. Langlois, R. C. Gallo, L. O. Arthur, P. J. Fishinger, D. P. Bolognesi, S. D. Putney, and T. J. Matthews. 1988. Antibodies that inhibit fusion of human immunodeficiency virus-infected cells bind a 24-amino acid sequence of the viral envelope gp120. Proc. Natl. Acad. Sci. USA 85:3198-3202.

35. Sanger, F. 1981. Determination of nucleotide sequences in DNA. Science 214:1205-1210.

36. Shelton, G. H., M. L. Linenberger, C. K. Grant, and J. L. Abkowitz. 1990. Hematologic manifestations of feline immunodeficiency virus infection. Blood 76:1104-1109.

37. Siebelink, K. H. J., I. Chu, G. F. Rimmelzwaan, K. Weijer, A. D. M. E. Osterhaus, and M. L. Bosch. 1992. Isolation and partial characterization of infectious molecular clones of feline immunodeficiency virus obtained directly from bone marrow DNA of a naturally infected cat. J. Virol. 66:1091-1097.

38. Siebelink, K. H. J., I. Chu, G. F. Rimmelzwaan, K. Weijer, R. van Herwijnen, P. Knell, H. F. Egberink, M. L. Bosch, and A. D. M. E. Osterhaus. 1990. Feline immunodeficiency virus (FIV) infection in the cat as a model for HIV infection in man: FIV-induced impairment of immune function. AIDS Res. Hum. Retroviruses 6:1373-1378.

39. Sparger, E. E., P. A. Luciw, J. H. Elder, J. K. Yamamoto, L. J. Lowenstine, and N. C. Pedersen. 1989. Feline immunodeficiency virus is a lentivirus associated with an AIDS-like disease in cats. AIDS 3:S42-S49.

40. Thali, M., U. Olshevsky, G. Furman, D. Gabuzda, M. Posner, and J. Sodroski. 1991. Characterization of a discontinuous human immunodeficiency virus type $1 \mathrm{gp} 120$ epitope recognized by a broadly reactive neutralizing human monoclonal antibody. J. Virol. 65:6188-6193.

41. Torten, M., M. Franchini, J. E. Barlough, J. W. George, E. Mozes, H. Lutz, and N. C. Pedersen. 1991. Progressive immune dysfunction in cats experimentally infected with feline immunodeficiency virus. J. Virol. 65:2225-2230.

42. Tozzini, F., D. Matteucci, P. Bandecchi, F. Baldinotti, A. Poli, M. Pistello, K. H. J. Siebelink, L. Ceccherini-Nelli, and $M$. Bendinelli. 1992. Simple in vitro methods for titrating feline immunodeficiency virus (FIV) and FIV neutralizing antibodies. J. Virol. Methods 37:241-252.

43. Wilson, C., M. Reitz, K. Aldrich, P. J. Klasse, J. Blomberg, R. C. Gallo, and M. Robert-Guroff. 1990. The site of an immune-selected point mutation in the transmembrane protein of human immunodeficiency virus type 1 does not constitute the neutralization epitope. J. Virol. 64:3240-3248.

44. Yamamoto, J. K., E. Sparger, E. W. Ho, P. R. Andersen, T. P. O'Connor, C. P. Mandell, L. Lowenstine, R. Munn, and N. C. Pedersen. 1988. Pathogenesis of experimentally induced feline immunodeficiency virus infection in cats. Am. J. Vet. Res. 49:1246-1258. 